\title{
Larval predation in malaria vectors and its potential implication in malaria transmission: an overlooked ecosystem service?
}

\author{
Olivier Roux ${ }^{1,2^{*}}$ and Vincent Robert ${ }^{1}$
}

\begin{abstract}
The role of aquatic predators in controlling the anopheline aquatic stage has been known for decades. Recently, studies have highlighted that exposition to predation stress during aquatic development can have a profound impact on life-history traits (e.g. growth rate, fecundity and longevity) and consequently on the ability of adults to transmit human malaria parasites. In this study, we present a review aiming to contextualize the role of Anopheles larvae predators as an ecosystem factor interacting with the malaria pathogen through its vector, i.e. the female adult Anopheles. We first envisage the predator diversity that anopheline vectors are susceptible to encounter in their aquatic habitats. We then focus on mosquito-predator interactions with a special mention to anti-predator behaviors and prey adaptations developed to deal with the predation threat. Next, we address the direct and indirect effects of larval predation stress on mosquito populations and on individual life-history traits, which strongly suggest some carry-over effect of the impact of larval predation on vectorial capacity. The last part addresses the impact of human activities on larval predation. Concluding remarks highlight gaps in the knowledge of anopheline bio-ecology which may constitute avenues for researchers in the future.
\end{abstract}

Keywords: Anopheles, Biological control, Carry-over effect, Environmental stress, Larval source management, Lifehistory trait, Non-consumptive effect, Oviposition, Vectorial capacity

\section{Background}

The productivity of larval habitats is a key factor which governs the size of mosquito populations and, in the case of anopheline vectors, the transmission of human malaria parasites. Like most short-term living organisms, anopheline mosquitoes present huge variations of adult density, depending on the more or less suitable conditions prevailing in larval habitats. Among the adverse conditions, predation is of primary importance. In his seminal paper published in 1958 "Predation on larvae of Anopheles gambiae Giles", M. Christie exposes a series of experimental studies before and after removing the natural fauna of a semi-permanent pool and gives a convincing demonstration of the great extent of predation [1].

*Correspondence: olivier.roux@ird.fr

${ }^{1}$ MIVEGEC Unit, IRD-CNRS, Université de Montpellier, Montpellier, France

Full list of author information is available at the end of the article
Malaria infections are a threat to about half of the world's population and are estimated to be responsible for more than 435,000 deaths in 2017, mainly in sub-Saharan Africa [2]. Long-lasting insecticide-treated nets are widely distributed and indoor residual spraying is recommended to limit human-vector contacts [2]. Rapid diagnostic tests are now available and bi-therapy drug administration is used to cure infection in patients. However, these methods are continuously challenged by the emergence and spread of both insecticide and drug resistances in the vectors and pathogens, respectively [2]. Unfortunately, because the blood-feeding habits of mosquitoes are a key behavior in the transmission process of malaria, and because it was thought that mosquitoes could be controlled with insecticides, other basic life-history traits, behaviors and ecologies remain deeply unexplored [3, 4]. Even though alternative control strategies are being investigated, they are still not efficient enough to lead to a long-term malaria control at moderate costs. 
Five species of Plasmodium, the pathogens responsible for malaria, are transmitted to humans by the bites of infected female Anopheles mosquitoes. To date, among the 488 species of Anopheles recognized as valid [5], about 60 are capable of transmitting Plasmodium to humans. Although Anopheles mosquitoes are cosmopolite and able to colonize various environments, most of these species occupy a specific niche. At a regional scale, Anopheles distribution is dictated by the larval aquatic stages, the most demanding in terms of biotic and abiotic conditions within the species. As larvae have a poor capacity to disperse, they often have to face challenging environments and grow under high stress levels. A growing body of literature indicates that environmental stresses (e.g. competition, predation or food shortage) experienced during larval development can have a profound impact on life-history traits (e.g. growth rate, fecundity and longevity) [6-9] which are important factors in pathogen transmission through changes in adult vectorial capacity that measures the transmission potential of a given infectious agent by a vector population [10-13].

Disease ecologists are increasingly realizing that species interactions influence the intensity of epidemics in wildlife populations $[14,15]$. As previously noted, the importance of predation of anophelines at aquatic stages has been known for decades, but renewed approaches shed light on the possible role of predation in disease dynamics demonstrating that predators can indirectly affect pathogen transmission through changes in host abundance (i.e. density-mediated effects) and through non-consumptive effects by altering the prey's phenotype and life-history traits. Predator-induced phenotypic changes can be especially pervasive in prey with discrete larval and adult stages for which exposure to biotic or abiotic stress during larval development can have strong carry-over effects on adult phenotypes [16, 17].

The role that predatory aquatic insects play as biocontrol agents in the natural regulation of larval and adult populations of mosquitoes has been known for a long time. However, the role of predators in pathogen transmission in mosquito-pathogen vectorial systems is overlooked. In this review, we contextualized the role of Anopheles larvae predators as an ecosystem factor interacting with the malaria pathogen through its vector, i.e. the female adult Anopheles. First, we briefly review the predator diversity that malaria vectors are susceptible to encounter in their aquatic habitats and describe their different specificities and efficiency at killing mosquito larvae. This part does not pretend to draw up an exhaustive list of all mosquito predators, nor of their complete characteristics, therefore in this regard, we suggest that the reader refers to the reviews cited in this section. The second part focuses on mosquito-predator interactions with a special mention to anti-predator behavior and prey adaptations. We then address the direct and indirect effects of larval predation on mosquito populations and on individual life-history traits, which lead to focus on the impact of larval predation stress on vectorial capacity. Finally, the last part addresses the impact of human activities on larval predation.

\section{Diversity of aquatic predators of anophelines}

Aquatic larval environments are highly challenging. Mosquito larval mortality from eggs to adults has been estimated to be over $90 \%[18,19]$. Mortality attributable to aquatic predators is highly variable ranging from 19 to $54 \%$ in rice fields in Thailand and up to $96 \%$ in Kenya [19, 20 ], and from $2 \%$ to $96 \%$ in a semi-field experiment in Kenya [21] depending on the environment, predator species and their density.

Aquatic communities, even in small ponds, are complex and include many organisms belonging to many taxa. Disentangling this diversity and defining what organisms are predators of Anopheles larvae can be done by direct behavioral observations, visual examination of gut contents after dissection or by the means of electrophoretic, immunological and molecular methods [18, 22-27]. Several excellent annotated lists or research works have described in detail the community of mosquito predators in general, including both terrestrial and aquatic predators $[23,28,29]$, as well as mosquito aquatic predators only [30-33] and more precisely, predators of Anopheles larvae [18, 22, 24, 34]. Most of these studies focused on rice fields or ponds but data on mosquitoes that thrive in forests (on ground level, in phytotelmata, in tree-holes, etc.) or in rivers or streams are scarce. Nevertheless, these studies revealed that the mosquito larvae predator community is mainly composed of aquatic vertebrates, arthropods and crustaceans.

Among the vertebrates, some amphibians are susceptible to be Anopheles larvae predators. Some tadpoles have been described to be associated to Anopheles aquatic habitats, but few of them have been identified as predators [18, 22, 24, 28, 35] and their appetite for Anopheles larvae is limited [20,36]. Fishes, however, have been extensively studied both in the laboratory and in the field for their ability to eat mosquito larvae and their use as mosquito biological control agents [31]. Among the large range of larvivorous fishes (see [31] for a review) some are particularly efficient at controlling Anopheles larvae in many types of reservoirs. The most well-known fishes which are predators of Anopheles larvae, are Gambusia affinis (the mosquito fish) and Poecilia reticulata (guppies) which have been extensively used all over the world in anti-malarial programs to control mosquito 
populations in different kinds of reservoirs. Gambusia affinis originated from the coast of the western USA but are able to thrive in a large range of water quality i.e. freshwater, brackish water and salt marshes, from $0{ }^{\circ} \mathrm{C}$ to $45{ }^{\circ} \mathrm{C}$, clear to turbid water, polluted urban water and in low dissolved oxygen concentration. They are sensitive to pesticides but are able to develop resistances [37, 38]. These large reaction norms to different abiotic conditions make G. affinis ideal for introduction in many parts of the world making this species the most widespread freshwater fish in the world [38, 39]. Poecilia reticulata is less flexible but has a tropical origin and consequently is adequate for use in malaria endemic areas. Both have shown high capacities to reduce the number of Anopheles larvae in laboratory and diverse aquatic habitats in the field, sometimes virtually clearing some villages from malaria cases for several years (but see [39-43]). However, the voracity of these two species, their ability to prey on almost any animal smaller than them without a real preference for mosquito larvae in the wild and their invasive nature gave rise to some concerns regarding negative environmental impacts [38, 39, 44]. Other fish species reported in Chandra et al. [31], for example Oryzias melastigma and Danio rerio, lowered the density of larvae and pupae of $76.2 \%$ and $86.8 \%$ in 6 days respectively and up to $100 \%$ in 12 days in rice fields. In barrels and containers, Aphanius dispar effectively reduced the breeding of An. arabiensis and An. gambiae by $97 \%$ in an urban area in Djibouti [31]. Another study has shown that the larval population of An. stephensi was reduced by $75 \%$ along the Goa coastal belt by Aplocheilus blocki [45]. Finally, it should be noted that the efficiency of fishes for really reducing malarial transmission, as predators of larval anophelines, is established in some cases but unproven in others [39, 42, 46].

Aquatic invertebrates are also very effective at killing mosquito larvae. They are more ubiquitous than fishes in relation to mosquito habitat types because of their ecological diversity, small size, short generation time, and, for insects, their ability for aerial colonization. Although preference for mosquitoes is common, aquatic invertebrate predators are polyphagous. Many of them are also rather generalist in their habitat selection [29]. In insects, several works have shown that the Hemiptera [with Notonectidae (backswimmers), Corixidae (water boatmans) and Nepidae (water scorpions)], the Coleoptera [with Hydrophilidae, Dytiscidae (water beetles)] and the Odonata (with dragonflies and damselflies) were the 3 main predator orders associated with Anopheles [1, 18, 47-53]. Their abundance is generally higher in permanent reservoirs [53] where they are less exposed than in temporary reservoirs which dry up. Their efficiency is highly variable depending on the habitat type, mosquito density and predator assemblage [30]. Some larvae of mosquito species are also larvivorous, the most efficient and the most studied being Toxorhynchites species (reviewed in [54]). These mosquitoes are cosmopolitan under the tropics and mainly inhabit tropical and subtropical forests. Females do not feed on blood but on plant liquid sources only, rich in carbohydrates. During their larval development they are able to feed upon 300-5000 mosquito larvae $[55,56]$ and exhibit a prepupal killing behavior during which they kill mosquito larvae without consuming them, including conspecific mosquitoes. They are resistant to starvation and fourthinstar larvae are able to stop their development during the dry season to emerge as adults during the first rains [57]. As they are more or less specialized in mosquito larvae feeding, females tend to search for water reservoirs with mosquito larvae and thus are able to disperse and to search for pools of water which are difficult to access for humans. However, they have a preference for very small shaded containers (tree-holes, tires, etc.) and thus preferentially prey upon Aedes species $[58,59]$ which in turn means they are poorly adapted for the control of Anopheles species in open environments even if some successes have been recorded [60]. Species of other mosquito genera such as Lutzia, Culiseta, Aedes and Culex present an intra-guild predation behavior toward other mosquito larvae, generally inhabit ground pools and can show some preferences for Anopheles larvae [29, 30, 61, 62]. Even cases of cannibalism of fourth-instar larvae on first-instar larvae have been observed [25].

Among crustacean, many copepods from the order Cyclopoida are known to prey upon mosquito larvae. Despite their small size $(0.5-1.5 \mathrm{~mm})$, they are able to attack prey twice their size. Although their consumption of mosquito larvae per copepod is moderate, they are very efficient at controlling mosquito populations because of their high reproductive capacity. Most of the cyclopoids are generalist predators but they can show a preference for Anopheles over Culex and Cladoceran [63]. They are virtually everywhere, from ground pool, rain-filled tires to bromeliad reservoirs [32, 64, 65] and can have access to larvae that usually escape from other predators in thick aquatic vegetation because of their tiny size. They also have the ability to resist to poor environmental conditions by entering dormancy (quiescence or diapause) and some species are able to resist the dryness of their reservoirs for months [66]. Copepods have been used to suppress Aedes populations in many villages in Asia and are also efficient at suppressing Anopheles populations [32]. Although their use did not show any environmental problems, they can represent a health risk in the few areas where Guinea worms (Dracunculus medinensis) remain as they are known to be an intermediate 
host of this parasite even though it is now almost eradicated [32].

Finally, most of the identified predators consume many other insect species and there is no evidence that any species preys exclusively on any of the anopheline mosquitoes [67]. The presence of a variety of predators in the aquatic habitats of anophelines is a necessary but insufficient condition of predation. Indeed, up to a certain level, some of the larvae succeed in surviving despite the presence of predators.

\section{How do mosquito larvae deal with predators?}

Predator-prey interactions are driven by an arm race in which the two protagonists attempt to develop strategies to survive. Predators endeavor to detect, recognize, catch and consume their prey and prey to detect, recognize and escape their predators. Consequently, predator-prey relationships play a central role in species evolution, ecology and community dynamics [68]. Here, we will focus on the prey perspective by exploring the strategies developed by mosquitoes, the consequences on their biology and on malaria transmission.

Once a predator detects a prey, the later has two options: to fight or to flee. Mosquito larvae and pupae have little choice between these options because their ability to fight is presumably null and their abilities to flee are limited, especially in small water bodies in which few or no places are safe from predators. Indeed, if most prey can leave their habitat when the predation threat is too high, mosquito larvae are often stuck in the water reservoir into which they have been laid (with the exception of species breeding in running water). Nevertheless, if mosquito larvae cannot fight nor flee for long, they are not sitting ducks waiting for predators either. In this line, mosquitoes have developed behavioral strategies to limit predation risk at both oviposition site selection and larval development levels.

For blood-feeding mosquitoes, the choice of an oviposition site is a critical step in the realization of individual fitness as well as in population dynamics and consequently in disease transmission [69]. As mosquito larvae are restricted in their movement, a bad choice in oviposition site by the females will deeply affect progeny survivorship. Consequently, females have developed a series of behaviors, strategies and senses to detect the best sites to lay their eggs [69]. The predation risk is among the characteristics gauged by female mosquitos to select an oviposition site. Chemical cues can be used either at distance or by direct contact with the water of the site [69-71]. The ability to detect water presenting a predation threat and avoid it for oviposition is common but not ubiquitous in mosquitoes (see [72] for a review). For example, G. affinis (fish) and Notonecta maculata (backswimmer) odors deter oviposition by Culex species and Culiseta longiareolata, respectively [71, 73-75]. Culiseta longiareolata also reacts to the physical presence of Anax imperator larvae (dragonfly) [76]. Oviposition response is frequently conditioned by the common evolutionary history between prey and their predators. Logically, preys that are not used to encountering a given predator generally display a low antipredator behavior [74, 77]. However, in Culex restuans, females did not react equally to three different species of predatory fishes that their progeny is susceptible to encounter and which represent the same level of threat to larvae [78]. In Culex pervigilans, females are able to detect larval predator Anisops wakefieldi (backswimmer) meaning that factors other than the common evolutionary history can be implied [79]. This is for example the case in the study by Blaustein et al. [75] in which the Chironomus riparius females (midge) do not detect N. maculata (backswimmer). It can be explained by the respective ecology of both the prey and the predator. Indeed, Chironomus larvae live at the bottom of the water reservoir and are protected by mud chimney, while backswimmers prey at the surface or in the water volume. Consequently, encounter probabilities are low, and the backswimmer is not a threat to the larvae. Sometimes, females are also able to detect the intensity of the threat level and lay their eggs in the least risky reservoirs [80].

In Anopheles species, few studies have been conducted on oviposition behavior related to predation risk. Nevertheless, Munga et al. [81] have shown that An. gambiae females were able to detect $N$. maculata on chemical bases and laid less eggs in presence of the predator. However, An. gambiae females did not use the same chemical compounds than $C$. longiareolata to gauge the predation risk [82]. Anopheles gambiae females are also able to detect fishes such as G. affinis and Carassius auratus [83].

As some predators are mobile from one aquatic habitat to another, the threat level gauged by ovipositing females is not necessarily the one larvae will experiment during their entire development. Consequently, larvae have also developed adaptations to escape predation threat or to minimize predation risk. In mosquitoes, adaptations are mainly behavioral with larvae tending to adopt a less conspicuous behavior in presence of a threat [8488]. In Anopheles gambiae (s.l.), a surface feeder which spends most of its time filtering for food at the water-air interface in the middle of the aquatic habitat, the detection of a predation risk (Anisops jaczewskii: Hemiptera, Notonectidae) induces a shift in behavior leading to a less active behavior (resting and feeding less) at the edges of the aquatic habitat $([86,87]$ but see $[89])$. The predation threat can be detected through different cues 
depending on the species [90,91]. In the An. gambiae complex, An. coluzzii, An. gambiae (s.s.) and An. arabiensis use chemical cues issued from a predation act and particularly cues originating from killed and pre-digested larvae. Anopheles arabiensis and An. gambiae (s.s.) also use physical cues such as predator vibrations [87]. However, the three species are sensitive to different chemical cue concentrations reflecting different threat sensitivities related to their respective ecology [92]. Indeed, $A n$. coluzzii mainly thrives in permanent reservoirs with a high predator density and many other organisms [53]. In this case, vibrations are certainly a poor information on the risk level and a too strong reaction to chemical cues could hinder the larval growth in an excessive way. Consequently, An. coluzzii larvae developed a gradual anti-predator response finely-tuned to the risk level to adjust the best trade-off between feeding and anti-predator behavior to minimize the cost of this anti-predator behavior (see below). In temporary reservoirs, shared by both An. gambiae and An. arabiensis, predators are less numerous, and the temporality of the water reservoir can induce frequent change in predator density. Consequently, as predators come and go, the presence of chemical cues is not necessarily instructive on the current risk level and physical cues, such as predator born-vibrations, could be used as an ultimate confirmation of the threat before triggering any anti-predator response [87]. These anti-predator behaviors allow prey to survive; however, such investments in anti-predator behavior have a cost and lead to direct and indirect impacts on individual lifehistory traits of the mosquito.

\section{Impact of larval predation stress on mosquito life-history traits and malaria transmission}

If prey-predator interactions were mainly broached from the prey consumption angle to determine their direct and indirect effects on prey density, recently, non-consumptive effects of predators on prey has been considered [93, 94]. It is now recognized that non-consumptive effects can be greater than consumptive effects [93, 95, 96]. Indeed, when under predation threat, individuals may adopt different resource allocation strategies to favor their direct survival to the detriment of growth, reproduction and self-maintenance [97]. Energy or time invested in a trait or a task cannot be invested in another one. Consequently, these trade-offs have a cost on different prey life-history traits, individual fitness and in fine on prey population dynamics $[94,97]$.

In mosquito larvae, including Anopheles species, the main defense line is behavioral. Faced with a predation risk, larvae adopt a less conspicuous behavior spending more of their time resting and less time feeding [84-88, 98]. According to the threat level, larvae adopt a trade-off between these two behaviors: the higher the threat level is, the lower the larval feeding rate is $[92,99,100]$. However, this trade-off has a cost on both larval development and survival as well as a non-intuitive carry-over effect on adult life-history traits $[6,8,12,83,101,102]$. Indeed, in An. coluzzii larvae exposed to the mere presence of backswimmers or fishes, the induced stress reduces larval survivorship and increases development duration [12, 83]. In adults, mosquito size, fecundity and survivorship are also negatively affected [12] as in other mosquito species $[6,8,101,102]$.

Lower food intake is probably not the only reason for the negative impact on life-history traits. Indeed, while under predation threats, prey are expected to allocate their resources to potential "fight-or-flight" situations and consequently convert less nutrients into body mass or reproduction (mainly proteins) to the benefit of carbohydrates in order to increase their metabolic rates (i.e. respiration) to fuel emergency functions [103-106]. Altogether, these physiological adaptations have effects on resource budgets, oxidative status, and thus long term life-history traits [103, 107-110]. Recently, predation stress has been shown to be a source of oxidative stress [107] affecting both enzymatic defenses [111$114]$ and life-history traits such as longevity, fecundity and mobility $[115,116]$. Indeed, an increased metabolic rate is associated to increased respiration [106, 117]. If this physiological change is beneficial to drive survival in a life-threatening situation, it may affect long-term body maintenance. Indeed, a higher oxygen consumption generates a higher level of reactive oxygen species which, if unbalanced by an anti-oxidant machinery, can lead to oxidative stress resulting in cumulative damages to lipids, proteins and DNA $[109,110,118]$. Damages to these molecules affect the structure and functioning of membranes, disturb signal transduction, reduce muscle efficiency, induce changes in secondary and tertiary structures of proteins jeopardizing enzyme functioning, induce base mutations with consequences on phenotypes and also shorten telomeres accelerating cell senescence ([118] and references therein). Altogether, oxidative challenges and damages have a cost on resources, cell homeostasis and body maintenance. However, oxidative stress induced by predation stress in mosquitoes has never been investigated and deserves more attention. All the life-history trait alterations mentioned above have effects beyond mosquito fitness alone. When the Anopheles are considered for their function as disease vectors, the reduction of their densities (through their direct consumption, larval mortality or fecundity reduction), the alteration of their energy budget, the reduction of their size and longevity are all important factors of their susceptibility to be infected by pathogens and their capacity 
to transmit these pathogens. Indeed, it has been shown that different larval stresses such as competition, parasitism or diet could reduce mosquito susceptibility to pathogens. For example, in Aedes sp., susceptibility to viruses (La Cross, dengue and Sindbis) was reduced when exposed to an inter- or intra-specific competition during the larval stage [119-121]. In Anopheles sp., susceptibility to Plasmodium sp. was also altered when previously infected with microsporidies [122-126] or exposed to food deprivation [13]. However, Roux et al. [12] failed to highlight any effect of larval predation stress on susceptibility to $P$. falciparum in An. coluzzii. Nevertheless, using an epidemiological model, Roux et al. [12] showed that the life-history trait alteration by larval predation stress should overall decrease malaria transmission mainly because of both lower fecundity and longevity which are important factors of the mosquitoes' vectorial capacity.

The mere presence of predators can also impact malaria epidemiology through oviposition behavior with females searching for aquatic habitats free of predators, thus impacting adult distribution, blood-meal frequency and survival. Indeed, females in search for adequate aquatic habitats are supposed to spend more time flying between aquatic habitats and blood-meal locations, increasing both oxidative stress and risk of aerial predation, reducing their energy budget and potentially taking fewer blood meals in their life ([72] and references therein; [127]). Altogether, larval predation shows complex effects on mosquitoes and pathogen transmission.

\section{How can human activities or interventions affect larval predation?}

The aim of larval source management is to modify mosquito aquatic habitats to reduce mosquito populations. It can be done through (i) the spread of chemical or biological larvicides; (ii) permanent habitat modifications (i.e. drainage); (iii) temporary habitat manipulations (i.e. flushing, shading, etc.); and (iv) the release of biological control agents (parasites or predators) (all reviewed in [128]). These actions can be done on purpose or for other goals but in all cases, they must be done with caution. Indeed, a poor management of such actions can lead to a reduction of predator pressures exerted on prey through the diminution of predator densities or by impeding predator movements. The consequence is a reduction of prey-predator interactions which leads to the disruption of ecosystem services provided by predators.

The most obvious way human activities or interventions impact larval predation effects is through the use of chemical pesticides and the presence of pollutants in water which affect aquatic biodiversity $[129,130]$. As chemical insecticides also kill competitors and predators, and because the mosquito population is more prone to recover than their predators and to develop resistances, indirect effects of insecticides on mosquito larvae can be counter-productive. Indeed, it has been reported that short term mosquito density can be increased by the use of insecticides because of the reduction of predator density [67, 131-133].

Land management such as land leveling to reduce the number of puddles, field draining, wetland destruction or management of river banks and lake shores have been a popular way to control mosquito aquatic habitats $[134,135]$. However, these methods reduce the structural complexity of the habitats and increase their isolation. Reduction in habitat structural complexity induces fewer shelters for both prey and predators. However, the absence of shelters increases intraguild predation (predator-predator interactions) which reduces predation pressure on prey $[136,137]$. The elimination of all mosquito aquatic habitats is difficult [138], thus land management tends to increase habitat isolation which is not a problem for mosquitoes which are good at dispersing. Moreover, because predators have lower local densities and larger spatial demands, they need more connected areas to maintain viable populations or to recover from stochastic extinctions due to insecticide use or their habitat drying up [139-141]. Consequently, habitat isolation negatively affects the abundance of many species of larval mosquito predators which can lead indirectly to an increase of mosquito densities [140, 142].

Irrigation schemes have been for a long time associated with an increase of mosquito populations by creating aquatic habitats such as paddy fields, irrigation canals and reservoirs $[135,143]$. Irrigation practices have been investigated and intermittent irrigation has been identified as a method for limiting the development of mosquito larvae, save water and increase yields. Its basic concept within the vector control strategies is to interrupt the reproductive cycle of the mosquito by withholding water on a periodic basis from the rice fields. Drying rice fields for 2-6 days induces a high larval mortality and decreased adult density. However, the results are mitigated, some nice successes lead to a complete interruption of larval development, a decrease of parasite prevalence and an increase of rice yields, some failures include extreme cases of adult density increases (see [144] for a review). Failures have been attributed to invertebrate community disturbance with mosquitoes recovering faster than their predators. The difficulty to achieve the desired dry conditions was also put forth and was due to residual water collections such as footprints which never dried-up and allowed a concentration of mosquito larvae $[134,145,146]$.

Urban areas are known to have a lower level of malaria endemicity than rural areas. This is assumed to be partly 
due to fewer Anopheles aquatic habitats which are frequently polluted and thus theoretically not favorable to larval development. However, the rapid growth of urban areas and the necessity to feed city populations increases urban and peri-urban agricultural irrigated sites which create larval aquatic habitats at the origin of most malaria cases $[35,147]$. Consequently, urban areas concentrate issues regarding the use of chemical pesticides and pollutants, land and irrigation managements. All these factors are susceptible to impede predator colonization and indirectly promote the development of Anopheles species by creating enemy-free spaces. Anopheles species also show a high level of phenotypic plasticity and, in some localities, urban polluted waters are not a constraint to their survival anymore [148-152]. Moreover, these polluted breeding sites are frequently poorly structured (no plants), temporal and isolated. Together, these factors prevent the progression of biological successions and prohibit aquatic predator colonization [136].

Human interventions, instead of attempting to suppress Anopheles aquatic habitats, which is very difficult in most areas, should favor actions improving predator diversity and density. There have been many attempts to use predators as biological control agents, but few have shown satisfying results on adult or larval density reduction (but see [153] for a review). Moreover, their efficiency was generally evaluated through surveys of larval densities and/or emergence rates in treated water reservoirs, but adult entomological surveys or epidemiological follow-ups were not performed, impeding a real evaluation of their efficiency at reducing malaria transmission. The lack of efficiency could be due to both the way predator potential is evaluated and the intrinsic characteristics of predators. Indeed, first, predator potential as a biological agent is frequently assessed in laboratory studies with simple experimental designs in which predators are starved to standardize their "appetite" and the number of larvae killed serves as reference for their efficiency. However, such data make no sense in the field where predator efficiency will depend on many different factors: its own density, the density of its prey, the presence of alternative prey or other predators, the size and type of reservoir, the synchrony of prey-predator cycles, the presence of shelters for prey and the predator's distribution in all the water reservoirs of the selected area. All this non-comprehensive list of factors has an impact on the density of mosquitos that will emerge from water reservoirs. Studies directly performed in the field give, most of the time, only an evaluation of what could be the productivity of a given water reservoir in the presence of the studied predator because all parameters cannot be quantified due to the difficulties inherent to the field. Consequently, the epidemiological impact of the use of predators to control mosquito populations can only be assessed in large trials along with epidemiological surveys. Secondly, a predator used as a biological agent has to be: a good self-disperser to reach all the breeding pools used by the mosquitoes; able to resist to the absence of mosquito larvae for long periods of time, either by entering dormancy or by feeding on alternative prey even though it has to show a strong preference for mosquito larvae; easy and cheap to rear (mass production, storage), easy to handle (release) and endure transport; should not be dangerous for the environment by creating a disequilibrium in the ecosystems in which it is introduced; should have a high reproductive capacity to limit rearing and release efforts over time ([33, 38], reviewed in $[153,154])$. Unfortunately, few of the potential candidates meet all these criteria.

It is worth noting that across this review, we have had to digress toward other mosquito species due to the lack of data regarding Anopheles. Even among other mosquito taxa, few data are available on the real impact of predation on disease transmission. This highlights gaps in the knowledge of anopheline bio-ecology and other mosquito vectors and may constitute many research avenues to work on in the future. Among them, researches could focus especially on the following topics:

- As stressors are different in permanent and temporary reservoirs, and because colonization and the development of the abilities of predators are different from those of mosquitoes, it would be useful to lead further investigations on the predator community according to the size of the reservoir, especially in very small reservoirs $(<1$ liter and about 10 days duration) such as footprints or phytothelmata which can be very productive in terms of mosquitoes but for which few data are available regarding predators.

- Mosquito predator communities in running water were also deeply neglected and need to be investigated to determine the type of pressure they exert on mosquito larvae and their impact on pathogen transmission.

- Any specific intervention on larval habitat (targeting or not predators) should include a follow-up of both predator diversity and densities. In the same way, both mosquito entomological surveys and pathogen epidemiological surveys should assess the sustainability of the intervention and the real impact of the intervention on pathogen transmission, respectively.

- Since testing and replicating all the potential experimental conditions and their combinations in both laboratory and field conditions is often time consuming, expensive and complicated to implement, modeling constitutes a strong potential alternative strategy to investigate the stressor effects. Moreover, as lar- 
val stress on pathogen transmission can be indirect, counter-intuitive and density- or species-dependent [12, 13, 155], modeling should allow better predictions on such impacts and could help to identify stressors that have synergetic or antagonistic effects.

- Finally, as rural populations can use pond water as drinking water for themselves and for animals, preservation of water quality by using natural predators, competitors or pathogens of mosquito larvae should be favored instead of the use of chemical insecticides. The benefits and drawbacks of using such control methods should be investigated with a One Health approach.

\section{Conclusions}

The increase of insecticide resistance has made it necessary to design new tools or improve existing methods to better control vector-borne diseases. In a context of environmental crisis and global changes, environmentally friendly methods should be encouraged. In most cases, the sole use of predators to control malaria mosquitoes is obviously insufficient. Nevertheless, a growing evidence of their direct and indirect effects on vector life-history traits and consequently on mosquito vectorial capacity and pathogen transmission was recently highlighted [6, $8,12,83,101,102]$ triggering a new interest in predation stress mechanisms in mosquitoes, and more broadly onto the effects of environmental components for malaria vectors and malaria transmission [156]. Effects of the introduction of predators as control agents on vector populations in the wild and on malaria transmission are difficult to predict because of the environmental conditions which are much more complex than in a laboratory. However, human intervention intending to favor colonization and preservation of natural aquatic predators could be enhanced by preserving natural habitats and favoring permanent reservoirs which are known to shelter higher predator densities than small and ephemeral reservoirs [53, 145]. Preservation of the predators' habitats could be part of sustainable and integrated vectormanagement strategies and could be a key component that helps to reduce both vector densities and malaria transmission through the enhancement of ecosystem services provided by predators or mosquito pathogens.

\section{Acknowledgements}

Not applicable.

\section{Funding}

Not applicable.

Availability of data and materials Not applicable.
Authors' contributions

OR and VR drafted the manuscript. Both authors read and approved the final manuscript.

\section{Ethics approval and consent to participate}

Not applicable.

\section{Consent for publication}

Not applicable.

\section{Competing interests}

The authors declare that they have no competing interests.

\section{Publisher's Note}

Springer Nature remains neutral with regard to jurisdictional claims in published maps and institutional affiliations.

\section{Author details \\ ${ }^{1}$ MIVEGEC Unit, IRD-CNRS, Université de Montpellier, Montpellier, France. \\ ${ }^{2}$ Institut de Recherche des Sciences de la Santé (IRSS), 01 BP 545, Bobo-Dioul- asso 01, Burkina Faso.}

Received: 28 January 2019 Accepted: 3 May 2019

Published online: 08 May 2019

\section{References}

1. Christie M. Predation on larvae of Anopheles gambiae Giles. J Trop Med Hyg. 1958;61:168-76.

2. WHO. World malaria report. 2018; http://www.who.int/malaria/publi cations/world-malaria-report-2018/en/.

3. Takken W. Chemical signals affecting mosquito behaviour. Invert Rep Dev. 1999;36:67-71.

4. Ferguson HM, Dornhaus A, Beeche A, Borgemeister C, Gottlieb M, Mulla MS, et al. Ecology: a prerequisite for malaria elimination and eradication. PLoS Med. 2010;7:e1000303.

5. Harbach RE. 2019. Mosquito taxonomic inventory. http://mosquitotaxonomic-inventory.info/. Accessed 14 Jan 2019.

6. Costanzo KS, Muturi EJ, Alto BW. Trait-mediated effects of predation across life-history stages in container mosquitoes. Ecol Entomol. 2011;36:605-15.

7. Muriu SM, Coulson T, Mbogo CM, Godfray HCJ. Larval density dependence in Anopheles gambiae s.s., the major African vector of malaria. J Anim Ecol. 2013;82:166-74.

8. van Uitregt VO, Hurst TP, Wilson RS. Reduced size and starvation resistance in adult mosquitoes, Aedes notoscriptus, exposed to predation cues as larvae. J Anim Ecol. 2012;81:108-15.

9. Telang A, Qayum AA, Parker A, Sacchetta BR, Byrnes GR. Larval nutritional stress affects vector immune traits in adult yellow fever mosquito Aedes aegypti (Stegomyia aegypti). Med Vet Entomol. 2012;26:271-81.

10. Shapiro LLM, Murdock CC, Jacobs GR, Thomas RJ, Thomas MB. Larval food quantity affects the capacity of adult mosquitoes to transmit human malaria. Proc R Soc Biol Sci. 2016;283:20160298.

11. Bara J, Rapti Z, Cáceres CE, Muturi EJ. Effect of larval competition on extrinsic incubation period and vectorial capacity of Aedes albopictus for Dengue virus. PLoS ONE. 2015;10:e0126703.

12. Roux $\mathrm{O}$, Vantaux $A$, Roche $B$, Yameogo KB, Dabiré KR, Diabaté $A$, et al. Evidence for carry-over effects of predator exposure on pathogen transmission potential. Proc R Soc Biol Sci. 2015;282:2430.

13. Vantaux A, Lefèvre T, Cohuet A, Dabiré KR, Roche B, Roux O. Larval nutritional stress affects vector life history traits and human malaria transmission. Sci Rep. 2016;6:36778.

14. Keesing F, Holt RD, Ostfeld RS. Effects of species diversity on disease risk. Ecol Lett. 2006;9:485-98.

15. Johnson PTJ, Hartson RB, Larson DJ, Sutherland DR. Diversity and disease: community structure drives parasite transmission and host fitness. Ecol Lett. 2008;11:1017-26.

16. De Block M, Stoks R. Fitness effects from egg to reproduction: bridging the life history transition. Ecology. 2005;86:185-97. 
17. Crean JA, Monro K, Marshall DJ. Fitness consequences of larval traits persist across the metamorphic boundary. Evolution. 2011;65:3079-89.

18. Service MW. Mortalities of immature stages of species B of Anopheles gambiae complex in Kenya-comparison between rice fields and temporary pools, identification of predators, and effects of insecticidal spraying. J Med Entomol. 1977;13:535-45.

19. Mogi M, Okazawa T, Miyagi I, Sucharit S, Tumrasvin W, Deesin T, et al. Development and survival of anopheline immatures (Diptera: Culicidae) in rice fields in northern Thailand. J Med Entomol. 1986;23:244-50.

20. Kweka EJ, Zhou GF, Gilbreath TM, Afrane Y, Nyindo M, Githeko AK, et al. Predation efficiency of Anopheles gambiae larvae by aquatic predators in western Kenya highlands. Parasit Vectors. 2011;4:7.

21. Howard AFB, Zhou G, Omlin FX. Malaria mosquito control using edible fish in western Kenya: preliminary findings of a controlled study. BMC Public Health. 2007;7:199.

22. Ohba SY, Kawada H, Dida GO, Juma D, Sonye G, Minakawa N, et al. Predators of Anopheles gambiae sensu lato (Diptera: Culicidae) larvae in wetlands, western Kenya: confirmation by polymerase chain reaction method. J Med Entomol. 2010;47:783-7.

23. Collins FH, Washino RK. Insect predators. In: Chapman HC, editor. Biological control of mosquitoes. Fresno, CA: American Mosquito Control Association Bulletin; 1985. p. 25-41.

24. Service MW. Mortalities of the larvae of Anopheles gambiae Giles complex and detection of predators by the precipitin test. Bull Entomol Res. 1973;62:359-69.

25. Koenraadt CJM, Takken W. Cannibalism and predation among larvae of the Anopheles gambiae complex. Med Vet Entomol. 2003;17:61-6.

26. Schielke E, Costantini C, Carchini G, Sagnon N, Powell J, Caccone A. Short report: development of a molecular assay to detect predation on Anopheles gambiae complex larval stages. Am J Trop Med Hyg. 2007;77:464-6.

27. Morales ME, Wesson DM, Sutherland IW, Impoinvil DE, Mbogo CM, Githure Jl, et al. Determination of Anopheles gambiae larval DNA in the gut of insectivorous dragonfly (Libellulidae) nymphs by polymerase chain reaction. J Am Mosquito Contr. 2003;19:163-5.

28. Jenkins DW. Pathognes, parasites and predators of medically important arthropods. Annotated list and bibliography. Geneva: WHO; 1964.

29. Mogi M. Insects and other invertebrate predators. J Am Mosquito Contr. 2007;23:93-109.

30. Shaalan EAS, Canyon DV. Aquatic insect predators and mosquito control. Trop Biomed. 2009;26:223-61.

31. Chandra G, Bhattacharjee I, Chatterjee SN, Ghosh A. Mosquito control by larvivorous fish. Indian J Med Res. 2008;127:13-27.

32. Marten GG, Reid JW. Cyclopoid copepods. J Am Mosquito Contr. 2007;23:65-92.

33. Quiroz-Martinez H, Rodriguez-Castro A. Aquatic insects as predators of mosquito larvae. J Am Mosquito Contr. 2007;23:110-7.

34. Ohba SY, Huynh TTT, Le LL, Ngoc HT, Hoang SL, Takagi M. Mosquitoes and their potential predators in rice agroecosystems of the Mekong delta, southern Vietnam. J Am Mosquito Contr. 2011;27:384-92.

35. Robert $\mathrm{V}$, Awono-Ambene HP, Thioulouse J. Ecology of larval mosquitoes, with special reference to Anopheles arabiensis (Diptera: Culcidae) in market-garden wells in urban Dakar, Senegal. J Med Entomol. 1998;35:948-55

36. Raghavendra K, Sharma P, Dash AP. Biological control of mosquito populations through frogs: opportunities \& constrains. Indian J Med Res. 2008;128:22-5.

37. Pyke GH. A review of the biology of Gambusia affinis and G. holbrooki. Rev Fish Biol Fisher. 2005;15:339-65.

38. Pyke GH. Plague minnow or mosquito fish? A review of the biology and impacts of introduced Gambusia species. Annu Rev Ecol Evol Syst. 2008;39:171-91

39. Walshe DP, Garner P, Abdel-Hameed Adeel AA, Pyke GH, Burkot T. Larvivorous fish for preventing malaria transmission. Cochrane Database Syst Rev. 2013. https://doi.org/10.1002/14651858.CD008090.pub2.

40. Ghosh SK, Tiwari SN, Sathyanarayan TS, Sampath TR, Sharma VP, Nanda $\mathrm{N}$, et al. Larvivorous fish in wells target the malaria vector sibling species of the Anopheles culicifacies complex in villages in Karnataka, India. Trans R Soc Trop Med Hyg. 2005;99:101-5.

41. Ghosh SK, Dash AP. Larvivorous fish against malaria vectors: a new outlook. Trans R Soc Trop Med Hyg. 2007;101:1063-4.
42. El-Sabaawi RW, FrauendorfTC, Marques PS, Mackenzie RA, Manna LR, Mazzoni R, et al. Biodiversity and ecosystem risks arising from using guppies to control mosquitoes. Biol Lett. 2016;12:20160590.

43. Chandra G, Ghosh A, Bhattacharjee I, Ghosh SK. Use of larvivorous fish in biological and environmental control of disease vectors. In: Cameron MM, Lorenz LM, editors. biological and environmental control of disease vectors. Wallingford: CABl; 2013. p. 25-41.

44. Bence JR. Indirect effects and biological control of mosquitoes by mosquitofish. J Appl Ecol. 1988;25:505-21.

45. Kumar A, Sharma VP, Sumodan PK, Thavaselvam D. Field trials of biolarvicide Bacillus thuringiensis var. israelensis strain 164 and the larvivorous fish Aplocheilus blocki against Anopheles stephensi for malaria control in Goa. India. J Am Mosquito Contr. 1998;14:457-62.

46. Yap HH. Biological control of mosquitoes, especially malaria vectors, Anopheles species. SE Asian J Trop Med. 1985;16:163-71.

47. Muiruri SK, Mwangangi JM, Carlson J, Kabiru EW, Kokwaro E, Githure J, et al. Effect of predation on Anopheles larvae by five sympatric insect families in coastal Kenya. J Vector Dis. 2013;50:45-50.

48. Darriet F, Hougard JM. Etude en laboratoire de la biologie et des capacités prédatrices de l'Hétéroptère aquatique Ranatra parvipes vicina (Signoret, 1880) à l'encontre des larves de moustiques. Rev Hydrobiol Trop. 1993;26:305-11.

49. Lozano RD, Rodriguez MH, Jimenez JIA, Avila MH, Mallorca C. Aquatic insects associated with Anopheles albimanus (Diptera: Culicidae) breeding sites in Southern Mexico. Environ Entomol. 1997;26:828-38.

50. Mogi M, Memah V, Miyagi I, Toma T, Sembel DT. Mosquito (Diptera, Culicidae) and predator abundance in irrigated and rain-fed rice fields in north Sulawesi, Indonesia. J Med Entomol. 1995;32:361-7.

51. Mogi M, Sunahara T, Selomo M. Mosquito and aquatic predator communities in ground pools on lands deforested for rice field development in Central Sulawesi, Indonesia. J Am Mosquito Contr. 1999;15:92-7.

52. Munga S, Minakawa N, Zhou G, Githeko AK, Yan G. Survivorship of immature stages of Anopheles gambiae s.l. (Diptera: culicidae) in natural habitats in western Kenya highlands. J Med Entomol. 2007;44:758-64.

53. Diabaté A, Dabiré RK, Heidenberger K, Crawford J, Lamp WO, Culler LE, et al. Evidence for divergent selection between the molecular forms of Anopheles gambiae: role of predation. BMC Evol Biol. 2008;8:5.

54. Collins LE, Blackwell A. The biology of Toxorhynchites mosquitoes and their potential as biocontrol agents. Biocontrol. 2000;21:105N-16N.

55. Steffan WA, Evenhuis NL. Biology of Toxorhynchites. Annu Rev Entomol. 1981;26:159-81.

56. Focks DA. Toxorhynchites - a biological control agent of containerbreeding mosquitoes. Am Mosquito Controller Bull. 1982;6:1-9.

57. Bradshaw WE, Holzapfel CM. Seasonal development of tree-hole mosquitoes (Diptera: Culicidae) and chaoborids in relation to weather and predation. J Med Entomol. 1984;21:366-78.

58. Zuharah WF, Fadzly N, Yusof NA, Dieng H. Risky behaviors: effects of Toxorhynchites splendens (Diptera: Culicidae) predator on the behavior of three mosquito species. J Insect Sci. 2015;15:128.

59. Focks DA. Toxorhynchites. In: Barr AR, Laird M, Weidhaas DE, editors. Biological control of mosquitoes. California: American Mosquito Control Association; 1985. p. 42-5.

60. Toohey MK, Goettel MS, Takagi M, Ram RC, Prakash G, Pillai JS. Field studies on the introduction of the mosquito predator Toxorhynchites amboinensis (Diptera: Culicidae) into Fiji. J Med Entomol. 1985;2:102-10.

61. Muturi EJ, Kim CH, Jacob B, Murphy S, Novak RJ. Interspecies predation between Anopheles gambiae s.s. and Culex quinquefasciatus larvae. J Med Entomol. 2010;47:287-90.

62. Surendran SN, Jude PJ, Thavaranjit AC, Eswaramohan T, Vinobaba M, Ramasamy R. Predatory efficacy of Culex (Lutzia) fuscanus on mosquito vectors of human diseases in Sri Lanka. J Am Mosquito Contr. 2013;29:168-70.

63. Kumar RM, Rao TR. Predation on mosquito larvae by Mesocyclops thermocyclopoides (Copepoda: Cyclopoida) in the presence of alternate prey. Int Rev Hydrobiol. 2003;88:570-81.

64. Marten GG, Astaiza R, Suarez MF, Monje C, Reid JW. Natural control of larval Anopheles albimanus (Dipetra, Culicidae) by the predator Mesocyclops (Copepoda, cyclopoida). J Med Entomol. 1989;26:624-7.

65. Marten GG, Nguyen M, Ngo G. Copepod predation on Anopheles quadrimaculatus larvae in rice fields. J Vector Ecol. 2000;25:1-6. 
66. Frisch D. Dormancy, dispersal and the survival of cyclopoid copepods (Cyclopoida, Copepoda) in a lowland floodplain. Freshwater Biol. 2002:47:1269-81

67. Collins CM, Bonds JAS, Quinlan MM, Mumford JD. Effects of the removal or reduction in density of the malaria mosquito, Anopheles gambiae sl, on interacting predators and competitors in local ecosystems. Med Vet Entomol. 2019;33:1-15.

68. Nosil P, Crespi BJ. Experimental evidence that predation promotes divergence in adaptive radiation. Proc Natl Acad Sci USA. 2006;103:9090-5

69. Bentley MD, Day JF. Chemical ecology and behavioral aspects of mosquito oviposition. Annu Rev Entomol. 1989;34:401-21.

70. Afify A, Galizia CG. Chemosensory cues for mosquito oviposition site selection. J Med Entomol. 2015;52:120-30.

71. Silberbush A, Markman S, Lewinsohn E, Bar E, Cohen JE, Blaustein L. Predator-released hydrocarbons repel oviposition by a mosquito. Ecol Lett. 2010;13:1129-38.

72. Vonesh JR, Blaustein L. Predator-induced shifts in mosquito oviposition site selection: a meta-analysis and implications for vector control. Isr J Ecol Evol. 2010;56:263-79.

73. Angelon KA, Petranka JW. Chemicals of predatory mosquitofish (Gambusia affinis) influence selection of oviposition site by Culex mosquitoes. J Chem Ecol. 2002;28:797-806.

74. Van Dam AR, Walton WE. The effect of predatory fish exudates on the ovipostional behaviour of three mosquito species: Culex quinquefasciatus, Aedes aegypti and Culex tarsalis. Med Vet Entomol. 2008:22:399-404

75. Blaustein L, Kiflawi M, Eitam A, Mangel M, Cohen JE. Oviposition habitat selection in response to risk of predation in temporary pools: mode of detection and consistency across experimental venue. Oecologia. 2004;138:300-5.

76. Stav G, Blaustein L, Margalith J. Experimental evidence for predation risk sensitive oviposition by a mosquito, Culiseta longiareolata. Ecol Entomol. 1999;24:202-7.

77. Ohba S-Y, Ohtsuka M, Sunahara T, Sonoda Y, Kawashima E, Takagi M. Differential responses to predator cues between two mosquito species breeding in different habitats. Ecol Entomol. 2012;37:410-8.

78. Silberbush A, Resetarits WJ. Mosquito female response to the presence of larvivorous fish does not match threat to larvae. Ecol Entomol. 2017:42:595-600.

79. Zuharah WF, Lester PJ. Can adults of the New Zealand mosquito Culex pervigilans (Bergorth) detect the presence of a key predator in larval habitats? J Vector Ecol. 2010;35:100-5.

80. Silberbush A, Blaustein L. Mosquito females quantify risk of predation to their progeny when selecting an oviposition site. Funct Ecol. 2011;25:1091-5.

81. Munga S, Minakawa N, Zhou GF, Barrack OAJ, Githeko AK, Yan GY. Effects of larval competitors and predators on oviposition site selection of Anopheles gambiae sensu stricto. J Med Entomol. 2006:43:221-4.

82. Warburg A, Faiman R, Shtern A, Silberbush A, Markman S, Cohen JE, et al. Oviposition habitat selection by Anopheles gambiae in response to chemical cues by Notonecta maculata. J Vector Ecol. 2011;36:421-5.

83. Chobu M, Nkwengulila G, Mahande AM, Mwang'onde BJ, Kweka EJ. Direct and indirect effect of predators on Anopheles gambiae sensu stricto. Acta Trop. 2015;142:131-7.

84. Juliano $S A$, Reminger $L$. The relationship between vulnerability to predation and behavior of larval treehole mosquitoes: geographic and ontogenetic differences. Oikos. 1992;63:465-76.

85. Ferrari MCO, Messier F, Chivers DP. Variable predation risk and the dynamic nature of mosquito antipredator responses to chemical alarm cues. Chemoecol. 2008;17:223-9.

86. Gimonneau G, Pombi M, Dabire RK, Diabate A, Morand S, Simard F. Behavioural responses of Anopheles gambiae sensu stricto $\mathrm{M}$ and $\mathrm{S}$ molecular form larvae to an aquatic predator in Burkina Faso. Parasit Vectors. 2012;5:11

87. Roux O, Diabate A, Simard F. Larvae of cryptic species of Anopheles gambiae respond differently to cues of predation risk. Freshwater Biol. 2013;58:1178-89.
88. Kesavaraju B, Juliano SA. Differential behavioral responses to waterborne cues to predation in two container-dwelling mosquitoes. Ann Entomol Soc Am. 2004;97:194-201.

89. Gimonneau G, Bayibeki AN, Baldet T, Awono-Ambene PH, Simard F. Life history consequences of larval foraging depth differ between two competing Anopheles mosquitoes. Ecol Entomol. 2014;40:143-9.

90. Kesavaraju B, Juliano SA. Nature of predation risk cues in container systems: mosquito responses to solid residues from predation. Ann Entomol Soc Am. 2010;103:1038-45.

91. Ferrari MCO, Wisenden BD, Chivers DP. Chemical ecology of predatorprey interactions in aquatic ecosystems: a review and prospectus. Can J Zool. 2010;88:698-724.

92. Roux O, Diabate A, Simard F. Divergence in threat sensitivity among aquatic larvae of cryptic mosquito species. J Anim Ecol. 2014;83:702-11.

93. Preisser EL, Bolnick DI, Benard MF. Scared to death? The effects of intimidation and consumption in predator-prey interactions. Ecology. 2005;86:501-9.

94. Benard MF. Predator-induced phenotypic plasticity in organisms with complex life histories. Annu Rev Ecol Evol Syst. 2004;35:651-73.

95. Lind J, Cresswell W. Determining the fitness consequences of antipredation behavior. Behav Ecol. 2005;16:945-56.

96. McCauley SJ, Rowe L, Fortin M-J. The deadly effects of "nonlethal" predators. Ecology. 2011;92:2043-8.

97. Lima SL, Dill LM. Behavioral decisions made under the risk of predation: a review and prospectus. Can J Zool. 1990;68:619-40.

98. Gimonneau G, Bouyer J, Morand S, Besansky NJ, Diabate A, Simard F. A behavioral mechanism underlying ecological divergence in the malaria mosquito Anopheles gambiae. Behav Ecol. 2010;21:1087-92.

99. Helfman GS. Threat-sensitive predator avoidance in damselfish-trumpetfish interactions. Behav Ecol Sociobiol. 1989;24:47-58.

100. Kesavaraju B, Damal K, Juliano SA. Threat-sensitive behavioral responses to concentrations of water-borne cues from predation. Ethology. 2007:113:199-206.

101. Alto BW, Malicoate J, Elliott SM, Taylor J. Demographic consequences of predators on prey: trait and density mediated effects on mosquito larvae in containers. PLoS ONE. 2012;7:e45785.

102. Beketov MA, Liess M. Predation risk perception and food scarcity induce alterations of life-cycle traits of the mosquito Culex pipens. Ecol Entomol. 2007;32:405-10.

103. Stoks R, De Block M, McPeek MA. Alternative growth and energy storage responses to mortality threats in damselflies. Ecol Lett. 2005:8:1307-16.

104. McPeek Mark A. The growth/predation risk trade-off: so what is the mechanism? Am Nat. 2004;163:E88-111.

105. McPeek MA, Grace M, Richardson JML. Physiological and behavioral responses to predators shape the growth/predation risk trade-off in damselflies. Ecology. 2001;82:1535-45.

106. Hawlena D, Schmitz OJ. Physiological stress as a fundamental mechanism linking predation to ecosystem functioning. Am Nat. 2010;176:537-56.

107. Janssens L, Stoks R. Predation risk causes oxidative damage in prey. Biol Lett. 2013;9:20130350.

108. Plaistow S, Siva-Jothy MT. Energetic constraints and male matesecuring tactics in the damselfly Calopteryx splendens xanthostoma (Charpentier). Proc R Soc Biol Sci. 1996;263:1233-9.

109. Costantini D. Oxidative stress and hormesis in evolutionary ecology and physiology. A marriage between mechanistic and evolutionary approaches. Berlin: Springer; 2014.

110. Selman C, Blount JD, Nussey DH, Speakman JR. Oxidative damage, ageing, and life-history evolution: where now? Trends Ecol Evol. 2012;27:570-7.

111. Slos S, Stoks R. Predation risk induces stress proteins and reduces antioxidant defense. Funct Ecol. 2008;22:637-42.

112. Guerra C, Zenteno-Savín T, Maeda-Martínez AN, Abele D, Philipp EER The effect of predator exposure and reproduction on oxidative stress parameters in the Catarina scallop Argopecten ventricosus. Comp Biochem Phys A. 2013;165:89-96.

113. Burraco P, Díaz-Paniagua C, Gomez-Mestre I. Different effects of accelerated development and enhanced growth on oxidative stress and telomere shortening in amphibian larvae. Sci Rep. 2017;7:7494. 
114. Pinya S, Tejada S, Capó X, Sureda A. Invasive predator snake induces oxidative stress responses in insular amphibian species. Sci Total Environ. 2016;566:57-62.

115. Janssens L, Stoks R. Chronic predation risk reduces escape speed by increasing oxidative damage: a deadly cost of an adaptive antipredator response. PLoS One. 2014;9:e101273.

116. Travers M, Clinchy M, Zanette L, Boonstra R, Williams TD. Indirect predator effects on clutch size and the cost of egg production. Ecol Lett. 2010:13:980-8.

117. Isaksson C, Sheldon BC, Uller T. The challenges of integrating oxidative stress into life-history biology. Bioscience. 2011;61:194-202.

118. Monaghan P, Metcalfe NB, Torres R. Oxidative stress as a mediator of life history trade-offs: mechanisms, measurements and interpretation. Ecol Lett. 2009;12:75-92.

119. Alto BW, Lounibos LP, Higgs S, Juliano SA. Larval competition differentially affects arbovirus infection in Aedes mosquitoes. Ecology. 2005;86:3279-88.

120. Alto BW, Lounibos $L P$, Mores $C N$, Reiskind $M H$. Larval competition alters susceptibility of adult Aedes mosquitoes to dengue infection. Proc $R$ Soc Biol Sci. 2008:275:463-71.

121. Bevins SN. Invasive mosquitoes, larval competition, and indirect effects on the vector competence of native mosquito species (Diptera: Culicidae). Biol Invasions. 2008;10:1109-17.

122. Bargielowski I, Koella JC. A possible mechanism for the suppression of Plasmodium berghei development in the mosquito Anopheles gambiae by the microsporidian Vavraia culicis. PLoS One. 2009;4:e4676.

123. Margos G, Maier WA, Seitz HM. The effect of nosematosis on the development of Plasmodium falciparum in Anopheles stephensi. Parasitol Res. 1992;78:168-71.

124. Bano L. Partial inhibitory effect of Plistophora culicis on the sporogonic cycle of Plasmodium cynomolgi in Anopheles stephensi. Nature. 1985;181:430

125. Hulls RH. The adverse effects of a microsporidan on sporogony and infectivity of Plasmodium berghei. Trans R Soc Trop Med Hyg. 1971:65:421-2.

126. Schenker W, Maier WA, Seitz HM. The effects of Nosema algerae on the development of Plasmodium yoelii nigeriensis in Anopheles stephensi. Parasitol Res. 1992;78:56-9.

127. Le Menach A, McKenzie FE, Flahault A, Smith DL. The unexpected importance of mosquito oviposition behaviour for malaria: non-productive larval habitats can be sources for malaria transmission. Malar J. 2005:4:23.

128. Tusting LS, Thwing J, Sinclair D, Fillinger U, Gimnig J, Bonner KE, et al. Mosquito larval source management for controlling malaria. Cochrane Database Syst Rev. 2013;8:CD008923.

129. Vonesh JR, Kraus JM. Pesticide alters habitat selection and aquatic community composition. Oecologia. 2009;160:379-85.

130. Marina CF, Bond JG, Muñoz J, Valle J, Novelo-Gutiérrez R, Williams T. Efficacy and non-target impact of spinosad, Bti and temephos larvicides for control of Anopheles spp. in an endemic malaria region of southern Mexico. Parasit Vectors. 2014;7:55.

131. Mesléard F, Garnero S, Beck N, Rosecchi É. Uselessness and indirect negative effects of an insecticide on rice field invertebrates. C R Biol. 2005;328:955-62.

132. Roberts $D R$, Andre RG. Insecticide resistance issues in vector-borne disease control. Am J Trop Med Hyg. 1994;50:21-34.

133. Meyabeme Elono AL, Foit K, Duquesne S, Liess M. Controlling Culex pipiens: antagonists are more efficient than a neonicotinoid insecticide. J Vector Ecol. 2018;43:26-35

134. Mutero CM, Blank H, Konradsen F, van der Hoek W. Water management for controlling the breeding of Anopheles mosquitoes in rice irrigation schemes in Kenya. Acta Trop. 2000;76:253-63.

135. Yasuoka J, Levins R, Mangioneb TW, Spielmanc A. Community-based rice ecosystem management for suppressing vector anophelines in Sri Lanka. Trans R Soc Trop Med Hyg. 2006;100:995-1006.
136. Carlson J, Keating J, Mbogo CM, Kahindi S, Beier JC. Ecological limitations on aquatic mosquito predator colonization in the urban environment. J Vector Ecol. 2004:29:331-9.

137. Carlson JC, Dyer LA, Omlin FX, Beier JC. Diversity cascades and malaria vectors. J Med Entomol. 2009:46:460-4.

138. Berg JA, Felton MG, Gecy JL, Landerman AD, Mayhew CR, Mengler JL, et al. Mosquito control and wetlands. Wetland Sci. 2010;27:24-34.

139. Holt RD, Hoopes MF. Food web dynamics in a metacommunity context: modules and beyond. In: Holyoak M, Leibold MA, Holt RD, editors. Metacommunities: spatial dynamics and ecological communities Chicago. Illinois: University of Chicago Press; 2005. p. 68-94.

140. Chase JM, Shulman RS. Wetland isolation facilitates larval mosquito density through the reduction of predators. Ecol Entomol. 2009:34:741-7.

141. Wilcox C. Habitat size and isolation affect colonization of seasonal wetlands by predatory aquatic insects. Israel J Zool. 2001;47:459-75.

142. Shulman RS, Chase JM. Increasing isolation reduces predator: prey species richness ratios in aquatic food webs. Oikos. 2007:116:1581-7.

143. Lacey LA, Lacey CM. The medical importance of riceland mosquitoes and their control using alternatives to chemical insecticides. J Am Mosquito Control. 1990;6:1-93.

144. Keiser J, Utzinger J, Singer BH. The potential of intermittent irrigation for increasing rice yields, lowering water consumption, reducing methane emissions, and controlling malaria in african rice fields. J Am Mosquito Control. 2002;18:329-40.

145. Mereta ST, Yewhalaw D, Boets P, Ahmed A, Duchateau L, Speybroeck N, et al. Physico-chemical and biological characterization of anopheline mosquito larval habitats (Diptera: Culicidae): implications for malaria control. Parasit Vectors. 2013;6:320.

146. Mogi M. Effect of intermittent irrigation on mosquitoes (Diptera, Culicidae) and larvivorous predators in rice fields. J Med Entomol. 1993;30:309-19.

147. Afrane YA, Klinkenberg E, Drechsel P, Owusu-Daaku K, Garms R, Kruppa T. Does irrigated urban agriculture influence the transmission of malaria in the city of Kumasi, Ghana? Acta Trop. 2004;89:125-34.

148. Gunathilaka N, Fernando T, Hapugoda M, Wickremasinghe R, Wijeyerathne P, Abeyewickreme W. Anopheles culicifacies breeding in polluted water bodies in Trincomalee District of Sri Lanka. Malar J. 2013;12:285.

149. Kamdem C, Tene Fossog B, Simard F, Etouna J, Ndo C, Kengne P, et al. Anthropogenic habitat disturbance and ecological divergence between incipient species of the malaria mosquito Anopheles gambiae. PLOS ONE. 2012:7:e39453.

150. Kamdem C, Fouet C, Gamez S, White BJ. Pollutants and insecticides drive local adaptation in african malaria mosquitoes. Mol Biol Evol. 2017:34:1261-75

151. Jones CM, Toé HK, Sanou A, Namountougou M, Hughes A, Diabaté A, et al. Additional selection for insecticide resistance in urban malaria vectors: DDT resistance in Anopheles arabiensis from Bobo-Dioulasso, Burkina Faso. PLoS ONE. 2012;7:e45995.

152. Awolola TS, Oduola AO, Obansa JB, Chukwurar NJ, Unyimadu JP. Anopheles gambiae s.s. breeding in polluted water bodies in urban Lagos, southwestern Nigeria. J Vector Dis. 2007:44:241-4.

153. Lacey LA, Orr BK. The role of biological control of mosquitoes in integrated vector control. Am J Trop Med Hyg. 1994;50:97-115.

154. Howard AFV. Control with arthropods. In: Cameron MM, Lorenz LM, editors. Biological and environmental control of disease vectors. Wallingford: CABl; 2013. p. 10-24.

155. Vantaux A, Ouattara I, Lefèvre T, Dabiré KR. Effects of larvicidal and nutritional stresses on Anopheles gambiae development, survival and competence for Plasmodium falciparum. Parasit Vectors. 2016;9:226.

156. Lefèvre T, Vantaux A, Dabiré KR, Mouline K, Cohuet A. Non-genetic determinants of mosquito competence for malaria parasites. PLoS Pathog. 2013;9:e1003365. 